\title{
Sudden unexpected death in epilepsy: basic mechanisms and clinical implications for prevention
}

\author{
Brian I Dlouhy, ${ }^{1}$ Brian K Gehlbach, ${ }^{2}$ George B Richerson ${ }^{3,4,5}$
}

\begin{abstract}
${ }^{1}$ Department of Neurosurgery, University of lowa, lowa City, Iowa, USA

${ }^{2}$ Department of Internal Medicine, University of lowa, Iowa City, lowa, USA

${ }^{3}$ Department of Neurology, University of lowa, lowa City, Iowa, USA

${ }^{4}$ Department of Molecular Physiology and Biophysics, University of lowa, lowa City, Iowa, USA

${ }^{5}$ Interdisciplinary Graduate Program in Neuroscience, University of lowa, lowa City, Iowa, USA
\end{abstract}

\section{Correspondence to}

Dr Brian J Dlouhy, Department of Neurosurgery, University of lowa Hospitals \& Clinics, 200 Hawkins Drive, lowa City, lowa 52242, USA; brian-dlouhy@ uiowa.edu

Received 9 June 2014 Revised 5 May 2015 Accepted 13 May 2015 Published Online First 2 June 2015

\section{CrossMark}

To cite: Dlouhy BJ, Gehlbach BK, Richerson GB. J Neurol Neurosurg Psychiatry 2016;87: 402-413.

\section{ABSTRACT}

Sudden unexpected death in epilepsy (SUDEP) is the most common cause of death in patients with intractable epilepsy. The substantial lifetime risk of SUDEP and the lack of a clear pathophysiological connection between epilepsy itself and sudden death have fuelled increased attention to this phenomenon. Understanding the mechanisms underlying SUDEP is paramount to developing preventative strategies. In this review, we discuss SUDEP population studies, case-control studies, witnessed and monitored cases, as well as human seizure cardiorespiratory findings related to SUDEP, and SUDEP animal models. We integrate these data to suggest the most probable mechanisms underlying SUDEP. Understanding the modifiable risk factors and pathophysiology allows us to discuss potential preventative strategies.

\section{INTRODUCTION}

Epilepsy patients are dying unexpectedly, without warning and without a clear understanding of how or why. ${ }^{1}$ Surprisingly, epilepsy patients, their family members and even many physicians, are unaware of the mortality and risk of sudden death associated with epilepsy. ${ }^{2}$ Sudden unexpected death in epilepsy (SUDEP) refers to the unpredictable and unanticipated death of a reasonably healthy individual with epilepsy, where no cause of death can be found. SUDEP is used to denote a diagnostic category to which these types of unexplained deaths are ascribed. Criteria have been established that define SUDEP as the sudden, unexpected, witnessed or unwitnessed, non-traumatic and nondrowning death of a person with epilepsy with or without a seizure, excluding documented status epilepticus, and in whom postmortem examination does not reveal a structural or toxicological cause of death. ${ }^{3}$ The criteria for SUDEP are merely a description of the clinical findings surrounding death and reflect our lack of understanding of the underlying pathophysiology. SUDEP has recently garnered considerable attention in the scientific literature due to its shockingly high prevalence in chronic refractory and surgical epilepsy patients, and lack of any well-defined mechanisms. ${ }^{1} \mathrm{~A}$ better understanding of the cause(s) of SUDEP is essential to develop objective criteria and biomarkers, identify high-risk individuals and provide preventative measures.

In this review, we discuss proposed mechanisms involved in the pathophysiology of SUDEP by integrating data from SUDEP epidemiological studies, witnessed and monitored SUDEP cases, human epilepsy research and epilepsy animal models of SUDEP. Lastly, we discuss what steps are being taken to prevent SUDEP.

\section{EPIDEMIOLOGY}

Incidence

Epidemiological studies on SUDEP have been heterogeneous in their methodology. Therefore, the reported incidence of SUDEP varies widely depending on the type and size of the study, the population analysed, the definition of SUDEP and how the cause of death was determined. ${ }^{1}$ Additionally, identifying SUDEP cases has been a challenge. Although examination of death certificates and coroners' cases are widely used, the term SUDEP is often not used to describe the cause of death when it is the appropriate diagnosis. ${ }^{4}$ Therefore, the incidence of SUDEP may be under-reported in some epidemiological studies.

Population-based studies reveal the lowest incidence as they consider all types of epilepsy, including very well-controlled epilepsy patients and patients in remission. The incidence of SUDEP is inversely related to remission of epilepsy. ${ }^{5}$ Ficker et al conducted a retrospective population-based study of 1535 epilepsy patients in Rochester, Minnesota from 1935 to 1994, which revealed an incidence of SUDEP that was 0.35 years $/ 1000$ person-years. Although the incidence was low in this study, the rate of sudden unexpected death was 24 times greater in young adults with epilepsy than in the general population. ${ }^{6}$ Including all population-based SUDEP studies, the incidence of SUDEP ranges from 0.09 to 2.3/1000-person years. In populations of individuals with more severe epilepsy, the incidence increases. The reported incidence in chronic refractory epilepsy patients ranges from 1.1 to $5.9 / 1000$ person-years. The highest reported incidence of SUDEP occurs in epilepsy surgery candidates or in patients who continue to have seizures after surgery, and ranges from 6.3 to $9.3 / 1000$ person-years. ${ }^{1}$

\section{Risk of death from SUDEP}

The low incidence of SUDEP in population-based studies belies the cumulative lifetime risk of death from SUDEP. In chronic refractory epilepsy patients who are seen in epilepsy referral centres, SUDEP is the leading cause of death, accounting for 10-50\% of all deaths. ${ }^{1}$ In a cohort study, children with epilepsy were found to have a $7 \%$ cumulative risk of dying suddenly within 40 years. Over this 40 -year period, SUDEP accounted for $38 \%$ of all deaths, almost all of which occurred in adulthood. ${ }^{7}$ The risk of death from SUDEP translates to a substantial 
health burden. Although the number of SUDEP deaths in comparison to many other neurological disorders is far smaller, SUDEP is second only to stroke in years of potential life lost. ${ }^{8}$

\section{SUDEP risk factors}

Examining details surrounding individual SUDEP cases has been crucial in identifying risk factors and revealing clues to the underlying mechanisms. These data come from large epidemiological studies, smaller case-control studies and observed cases. Most SUDEP cases are unwitnessed, however, circumstantial and physical evidence suggests that SUDEP usually follows a generalised tonic clonic seizure (GTCS). ${ }^{9} 10$ Supporting this, most witnessed SUDEP cases have occurred after a GTCS. ${ }^{11}$

Case-control studies of SUDEP and non-SUDEP epilepsy deaths have determined risk factors specific for SUDEP. Although risk factors vary due to the heterogeneity of studies, some risk factors are common to many of the studies. ${ }^{12}$ SUDEP occurs in all ages, and the ages of reported cases have ranged from 8 months to 83 years. ${ }^{5}$ Typically, the mean age at death in most studies is between 25 and 39 years, and, in general, ages between 20 and 40 years are considered to be associated with the highest risks for SUDEP. ${ }^{5}$ Ethnicity and gender are unlikely to significantly affect SUDEP risk. An increase in duration of epilepsy and earlier age of onset of epilepsy are often-cited risk factors for SUDEP. ${ }^{12}$ Whether these are independent risk factors is unclear. One of the strongest and most often cited risk factor for SUDEP is an increased frequency of GTCS. ${ }^{5} 12$ This provides supportive evidence that SUDEP results from a seizure.

Although one would presume that better control of seizures through antiepileptic drugs (AEDs) would lead to a decrease in SUDEP, some case-control studies have identified AED polytherapy, ${ }^{12}$ as well as lamotrigine ${ }^{12}{ }^{13}$ and carbamazepine, ${ }^{14}{ }^{15}$ as risk factors for SUDEP. However, these findings are difficult to interpret since polytherapy can be a surrogate for more severe epilepsy. Additionally, across epidemiological studies, these findings are inconsistent. ${ }^{12} 16{ }^{17}$ Increasing evidence from metaanalyses and randomised controlled studies suggests that monotherapy and polytherapy at efficacious doses reduce SUDEP. ${ }^{18}$ Although it appears that AEDs are not associated with an increased risk for SUDEP on a population level, some epilepsy patients may be susceptible to effects of AEDs through direct or indirect effects on the heart and autonomic system. ${ }^{19}$

Although identifying risk factors for SUDEP has been extremely important, many patients with these risk factors do not die, suggesting that other major causal mechanisms are involved.

\section{Witnessed and monitored SUDEP cases}

Witnessed SUDEP cases and cases from epilepsy monitoring units (EMUs) have provided the greatest insight to understanding the key contributory mechanisms underlying SUDEP.

\section{Witnessed SUDEP cases}

Witnessed SUDEP cases are infrequent. In a study of 15 witnessed SUDEP cases, 12 occurred in association with a GTCS. ${ }^{11}$ In two cases, the patient was postictal, and in one case, the patient was suspected to have an aura preceding death. In 12 cases, witnesses commented that the individuals had difficulty breathing, suggesting a respiratory component to the cause of death. Seven of the 15 cases occurred while in bed, suggesting that sleep and the patient's level of arousal and the position of the face, mouth and chest may predispose epilepsy patients to SUDEP. $^{11}$
Video EEG-monitored SUDEP cases

Fortunately, EMU SUDEP cases are extraordinarily rare. In two cases, death occurred after GTCS triggered respiratory dysfunction, hypoxaemia and cardiac events. ${ }^{20} 21$ In another case, seizures followed by asphyxia while in the prone position led to death. ${ }^{22}$ In other cases, postictal cessation of cerebral function was followed by cardiorespiratory failure. ${ }^{23}{ }^{24}$ Although these case reports are limited, their conclusions were supported by the MORTality in Epilepsy Monitoring Unit Study (MORTEMUS), ${ }^{25}$ a retrospective review of SUDEP and near-SUDEP cases from 147 EMUs across the world. This study detailed the events surrounding 16 SUDEP cases, of which 11 had VEEG at the time of death. In all 11 monitored cases, GTCS immediately preceded death. Of the 14 SUDEP cases for which position of the patient could be assessed, 13 were in the prone position at the time of cardiorespiratory arrest, often with the face partly tilted to one side.

It was not possible to evaluate cardiac or respiratory activity during the fatal seizure for any of the patients. Among the 11 VEEG monitored cases, there were nine patients in whom heart rate and breathing movements could be assessed by an expert panel from the time the GTCS ended until death occurred. Seizures were followed by a short period of normal or increased heart and respiratory rates, after which there was "early postictal parallel collapse of respiratory and cardiac rates, which was observed in every patient during the first 3 min postictally". This was accompanied by postictal generalised EEG suppression (PGES). The early cardiorespiratory collapse was terminal in three of the patients. In the remaining six patients, there was transient restoration of cardiac function associated with abnormal and possibly ineffective respiration, likely aggravated by the prone position. Respiration then progressively deteriorated until terminal apnoea occurred, followed by terminal asystole. In every case, terminal apnoea occurred first, and the heart rate continued for a variable period of time before terminal asystole (figure 1). Analysis of individual cases reveals that in many patients breathing was markedly abnormal or absent for long periods during which there was a heart rate that could often be normal for a significant period of time (figure 2). These data must be interpreted with the understanding that blood pressure was not measured and it is possible that there was some ventilation that occurred but was not seen on videotape.

\section{PATHOPHYSIOLOGY}

The combination of SUDEP risk factors, clues from witnessed SUDEP cases, EMU monitoring of SUDEP cases, physiological data obtained from non-fatal seizures in epilepsy patients and data from animal models have led to many proposed pathophysiological mechanisms underlying SUDEP. Most SUDEP cases occur after a GTCS. ${ }^{9}$ Therefore, it is unlikely that SUDEP results strictly from something inherent or intrinsic to epilepsy and unrelated to seizure events, and it suggests that seizures themselves induce pathophysiological changes that play a major role in SUDEP. However, as will be discussed, seizure-induced cardiorespiratory changes are likely only one aspect to the pathophysiology of SUDEP, which appears complex and multifactorial, and may involve a variety of other factors such as loss of arousal, time of day, position of the patient during the seizure, intrinsic pulmonary and cardiac dysfunction, and genetic mutations that predispose epilepsy patients to seizureinduced cardiorespiratory dysfunction.

\section{Respiratory}

Seizure-induced respiratory changes

In 1899, Hughlings Jackson reported that, with "slight epileptic attacks, les petits maux, the patient 'turns blue' or 'purple'". ${ }^{26}$ 


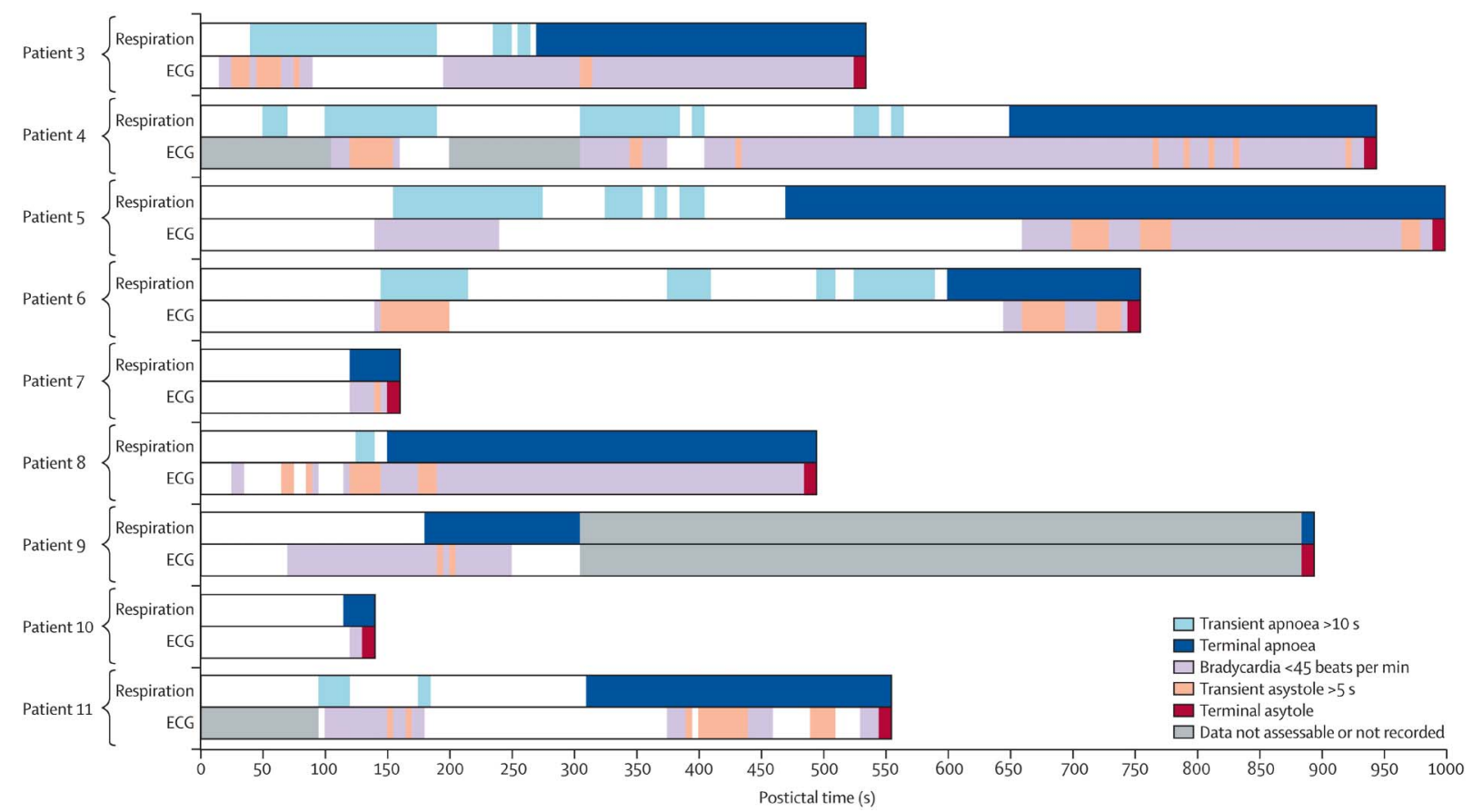

Figure 1 Patterns of postictal cardiorespiratory functions in video EEG-monitored sudden unexpected death in epilepsy (SUDEP) cases. Nine cases of SUDEP demonstrating the individual patterns of postictal cardiorespiratory function before death are illustrated. Transient episodes of apnoea $(>10 \mathrm{~s})$, asystole $(>5 \mathrm{~s})$ and bradycardia $(<45 \mathrm{bpm})$ are shown, together with terminal apnoea and asystole. Cardiorespiratory abnormalities were always observed during the first 3 min postictally, often concomitantly. In each case, terminal apnoea proceeded terminal asystole for varying lengths of time. From Ryvlin, Lancet Neurology, $2013 .^{25}$

Over the following century, the notion that seizures could impair breathing was supported by scattered reports describing hypoventilation (including apnoea) and oxygen desaturation in patients with either generalised or focal seizures. ${ }^{27-29}$ The frequency with which seizures result in respiratory dysfunction was not fully appreciated until recently, because hypoventilation (including apnoea) can easily go unnoticed unless respiratory parameters are directly measured. Respiratory monitoring has rarely been employed in EMUs. For example, none of the SUDEP cases in the MORTEMUS study included any measurements of breathing, even $\mathrm{SaO}_{2}$. Recently, however, investigations that have employed respiratory monitoring techniques used in polysomnography, including the analysis of respiratory effort (using respiratory inductance plethysmography belts), oronasal airflow (using nasal pressure transducers and oronasal thermistry), $\mathrm{SaO}_{2}$ and end tidal $\mathrm{CO}_{2}\left(\mathrm{ETCO}_{2}\right)$, have shed light on the frequency and severity of peri-ictal respiratory dysfunction.

It is clear from these studies that ictal respiratory dysfunction is common during seizures and can be severe. In a study by Nashef et $a l^{30}, 10$ of 17 (59\%) patients undergoing longterm video EEG monitoring exhibited apnoea concurrent with seizures, with $\mathrm{SaO}_{2}$ falling below $85 \%$ in six. More recently, Bateman et $a l^{31}$ analysed 304 seizures in 56 patients with intractable localisation-related epilepsy. In this cohort, $\mathrm{SaO}_{2}$ decreased below $90 \%$ in $33.2 \%$ of seizures and below $70 \%$ in $3.6 \%$ of seizures. Desaturation was not limited to generalised seizures: indeed, the $\mathrm{SaO}_{2}$ decreased below 90\% in $34 \%$ of partial seizures. Central apnoea or hypopnoea occurred with $50 \%$ of 100 seizures in which nasal airflow and respiratory effort were measured, while mixed or obstructive apnoeas were present in $9 \%$ of seizures. Analysis of $\mathrm{ETCO}_{2}$ levels in this study ${ }^{31}$ and in a subsequent one ${ }^{32}$ by the same investigators, revealed that seizures were frequently associated with severe and prolonged increases in $\mathrm{ETCO}_{2}$ levels, to a level exceeding $50 \mathrm{~mm} \mathrm{Hg}$ in 11 of 33 patients and in 35 of 94 recorded seizures. Other investigators have reported a similar frequency of ictal hypoxaemia in adults and children with epilepsy. ${ }^{33-35}$

\section{Intrinsic pulmonary dysfunction}

Interestingly, hypercapnia and oxygen desaturation appear in many patients to extend well into the postictal period, during which time respiratory effort has been reported to be qualitatively preserved or even increased, suggesting the possibility of intrinsic pulmonary dysfunction. ${ }^{32}{ }^{36}$ Conceivably, seizures may cause ventilation/perfusion mismatch through alterations in pulmonary blood flow and/or venous return. In the absence of direct measurements of minute ventilation or blood gases, however, the evidence in support of the hypothesis that intrinsic pulmonary dysfunction is a major contributor to peri-ictal hypoxaemia, or to SUDEP itself, is currently circumstantial.

Pulmonary oedema of varying severity has been found on autopsy in many SUDEP cases. ${ }^{25}{ }^{37-39}$ However, in the majority of cases, the oedema is mild and not felt to be significant enough to cause death. ${ }^{25}$ The aetiology of the oedema is not clear. Some have postulated that the oedema is a consequence of pulmonary vascular causes and terminal cardiac arrest. ${ }^{1}$

Prone positioning and postictal loss of arousal

Given the frequency and severity of seizure-induced respiratory abnormalities, it is perhaps surprising that death does not occur more often. If peri-ictal respiratory dysfunction is capable of causing death, what additional factors are required for SUDEP to occur? It may be that ictal respiratory dysfunction is only dangerous in certain circumstances. As noted above, patients who die of SUDEP are frequently found prone in bed. ${ }^{11} 25$ In such a position, the mouth and nose may be wholly or partly occluded, and 

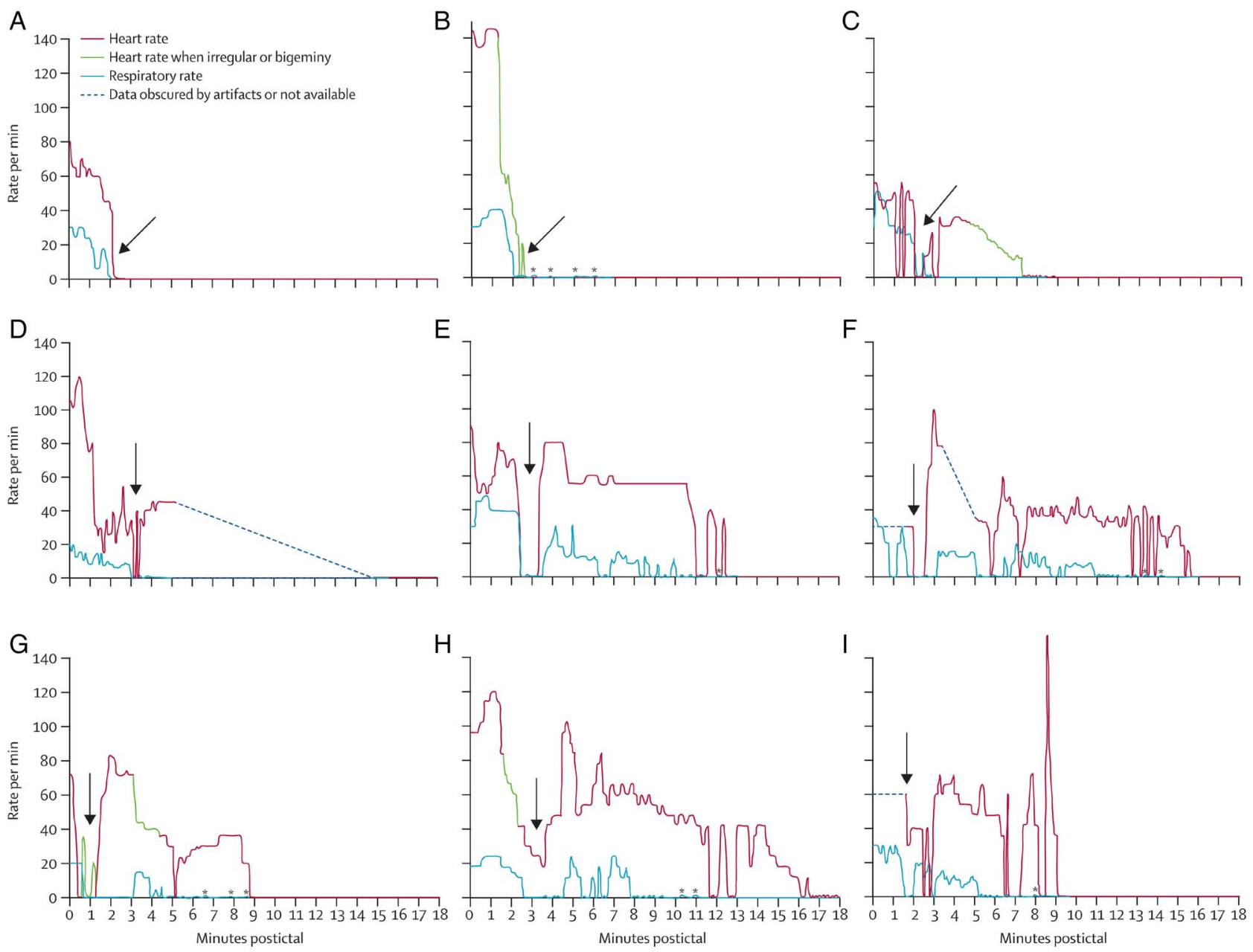

Figure 2 Cardiorespiratory function in video EEG-monitored sudden unexpected death in epilepsy (SUDEP) cases. Individual patterns of postictal cardiorespiratory functions from SUDEP cases, starting from the end of each fatal seizure, in patients with video EEG-monitored SUDEP for which both respiration and heart rates could be measured by an expert panel. The black arrows indicate the early postictal collapse of respiratory and cardiac rates during the first 3 min postictally, leading to immediate death in three patients $(A-C)$. A similar pattern was observed in another case (D) for which transient arrest of recording occurred. In other cases $(E-I)$, cardiorespiratory functions were transiently and partially restored, until terminal apnoea occurred, followed by terminal asystole. From Ryvlin, Lancet Neurology, 2013. ${ }^{25}$

it may take more muscular effort to expand the chest, increasing the risk of rebreathing or asphyxia if the patient fails to achieve arousal. As noted in the MORTEMUS study, "patients who died of SUDEP were not seen to take any corrective action to optimise their position and remained in the same position from seizure end until death". The epilepsy patient has therefore apparently lost the normal arousability from hypercapnia, ${ }^{40}$ which should occur from seizure-induced hypoventilation. Possible mechanisms for this include suppression of brainstem arousal centres and loss of consciousness that occurs in GTCS and complex partial seizures. Serotonergic neurons in the midbrain contribute to the ascending arousal system, whereas serotonergic neurons in the medulla stimulate breathing. ${ }^{40-42}$ Both are activated by hypercapnia. Postictal depression of serotonergic activity could impair breathing and reflexive repositioning if the mouth and nose are obstructed by bedding.

\section{Sleep and breathing}

The temporal clustering of deaths at night ${ }^{25}$ also suggests the possibility that SUDEP risk is influenced by circadian or sleepwake processes that influence breathing and vigilance. ${ }^{43}$ Breathing during sleep differs from that during wakefulness in a variety of ways that have the potential to increase risk.
Breathing is inherently unstable at sleep onset as respiratory stimuli related to wakefulness and behavioural influences are withdrawn. ${ }^{44}$ Many otherwise healthy participants exhibit hypoventilation or frank apnoea during this transition. Sleep is associated generally with a reduction in the ventilatory response to hypoxia and hypercapnia as well as with a reduced response to ventilatory loading. ${ }^{45-47}$ Upper airway dilator tone also decreases during sleep (particularly rapid eye movement sleep), leading to obstructive apnoeas in susceptible individuals. ${ }^{48}$ Interestingly, recent studies suggest that sleep apnoea may be more common in patients with epilepsy ${ }^{49} 50$ and may be linked to poor control of seizures. ${ }^{51}$ Finally, circadian influences may also play a role in SUDEP. A circadian propensity to seizure occurrence has been shown in animals, ${ }^{52}$ while seizures themselves affect sleep-wake processes differently depending on their circadian timing. ${ }^{53}$ In addition, the circadian timing system plays an important role in modulating vigilance and control of breathing. ${ }^{5455}$ To date, this area has received little attention.

Secondary cardiac effects from pulmonary dysfunction

Rather than being viewed as entirely 'respiratory' or 'cardiac' in aetiology, some deaths may reflect individual cardiac susceptibilities to peri-ictal respiratory dysfunction. Peri-ictal hypoxaemia 
has been shown to be associated with QT prolongation and shortening, ${ }^{56}$ suggesting that in some cases abnormalities in cardiac repolarisation may be induced by respiratory dysfunction. Similarly, hypoxaemia reliably leads to bradycardia when the patient is apnoeic. ${ }^{57} 58$ In a study performed in the $1940 \mathrm{~s},{ }^{59}$ participants who fainted in response to acute hypoxia exhibited pronounced bradycardia, muscle vasodilation and apnoea, when compared with those who did not, providing an early illustration of individual differences in the response to acute hypoxia. ${ }^{60}$ Conceivably, the association between certain cardiac gene mutations and SUDEP risk may be partly mediated by cardiac susceptibility to peri-ictal respiratory dysfunction.

Collectively, these data indicate that peri-ictal respiratory dysfunction is common and can be severe, at least among patients admitted to inpatient EMUs. ${ }^{25}$ Little is known about the mechanisms responsible for this dysfunction. Peri-ictal hypoxaemia is associated with EEG evidence of contralateral spread ${ }^{61}$ as well as with PGES. ${ }^{36}$ Conceivably, these associations may reflect the spread of seizures into respiratory control centres of the brainstem. ${ }^{2}$ In the 1950 s, it was shown that apnoea could be produced by the intraoperative stimulation of various targets within the frontal and temporal lobe. ${ }^{62}$ Whether a similar mechanism is responsible for peri-ictal respiratory dysfunction is not known.

\section{Animal models of SUDEP and serotonin dysfunction as a} molecular mechanism

Additional evidence supporting a respiratory mechanism for SUDEP comes from animal models and the study of the molecular mechanisms underlying the control of breathing. Some mouse species and genetically altered mice develop spontaneous or provoked seizures, which leads to death. These mouse models have allowed researchers to examine the cardiorespiratory events proceeding death. In both DBA/1 and DBA/2 mice, audiogenic seizures lead to respiratory arrest and death. ${ }^{63-65}$ In DBA/1 mice, seizure-induced death is prevented by resuscitation using a polyethylene tube placed over the nostrils of the mice and connected to a rodent respirator. ${ }^{63}$ In $\mathrm{DBA} / 2$ mice, similar findings are observed as oxygenation prevents death after seizure. ${ }^{64}$ Fluoxetine, which is a selective serotonin reuptake inhibitor, has been shown to reduce the incidence of respiratory arrest in $\mathrm{DBA} / 1^{66}$ and DBA/2 mice ${ }^{65} 67$ after audiogenic seizures, suggesting serotonin $(5-\mathrm{HT})$ may play a role in the molecular mechanisms underlying seizure-induced hypoventilation. Additionally, 5-HT receptor expression in DBA mice exhibits abnormal levels, including reductions of 5-HT2C levels. ${ }^{68}$

5-HT neurons found in the medullary raphe act as central chemoreceptors that regulate $\mathrm{PCO}_{2}$ and $\mathrm{pH}$ and project to key respiratory neurons throughout the brainstem to stimulate breathing. ${ }^{69} \mathrm{Lmx} 1 \mathrm{~b}^{\mathrm{f} / \mathrm{f} / \mathrm{p}}$ mice, which lack $>99 \%$ of 5 -HT neurons in the central nervous system by genetic deletion in utero, exhibit high rates of apnoea and death during the early postnatal period along with defects in arousal to an increase in ambient $\mathrm{CO}_{2}$ during sleep. ${ }^{40}{ }^{70}$ Compared to littermate controls, $\mathrm{Lmx} 1 \mathrm{~b}^{\mathrm{f} / \mathrm{f} / \mathrm{p}}$ mice have a lower seizure threshold and increased seizure-induced mortality, suggesting that serotonin neurons raise the seizure threshold and decrease seizure-related mortality. ${ }^{71}$ Breathing ceased during most seizures without recovery, whereas cardiac activity persisted for up to $9 \mathrm{~min}$ before terminal arrest. The mortality rate of the $\mathrm{Lmx} 1 \mathrm{~b}^{\mathrm{f} / \mathrm{f} / \mathrm{f}}$ ${ }^{\mathrm{p}}$ mice as well as the littermate controls was reduced by mechanical ventilation during the seizure. Both of these findings suggest that death ensued first from respiratory failure, followed by terminal asystole. In another study, deletion of $5-\mathrm{HT}_{2 \mathrm{c}}$ receptors in mice led to recurrent seizures and sudden death. ${ }^{72}$ These various rodent models suggest serotonin dysfunction may play a role in SUDEP.
Translating these findings to humans, in a retrospective study of patients with medically refractory partial epilepsy, serotonin reuptake inhibitors were found to be associated with reduced severity of ictal hypoxaemia. ${ }^{73}$ Imaging findings help support a role for brainstem respiratory dysfunction in the pathophysiology of SUDEP. Compared to controls, MRI revealed greater volume loss in the mesencephalon in two individuals who died from SUDEP compared to 30 individuals with temporal lobe epilepsy (TLE). ${ }^{74}$

\section{Summary}

There is growing evidence supporting respiratory dysfunction as a cause of SUDEP. Although some have been long-time proponents of a respiratory dysfunction theory for $\mathrm{SUDEP}^{30}$ this is a major divergence from the previous majority, which held that SUDEP was primarily due to cardiovascular dysfunction. Although serotonin has been implicated in mouse models of SUDEP, many questions remain regarding the potential mechanisms and triggering factors involved in peri-ictal hypoventilation that leads to death.

\section{Cardiac}

Seizure-induced cardiac changes

In the general population, sudden cardiac death has garnered considerable scientific and public attention. Unlike many sudden cardiac deaths, no structural cause of death can be found in SUDEP. $^{10}$ However, seizures do induce a variety of transient cardiac effects. These include changes in heart rate, arrhythmias, asystole and various other ECG abnormalities, some potentially lethal. Additionally, epilepsy may predispose patients to cardiac autonomic dysfunction. Genetic diseases known to affect the heart may also result in epilepsy, predisposing certain epilepsy patients to SUDEP.

Seizures induce various transient heart rate changes. In a study by Opherk et al, ${ }^{75}$ of 102 seizures in 41 patients, 99\% of the seizures led to an increase in heart rate. In this study, sinus tachycardia (HR>100 bpm) occurred in 100\% of generalised seizures and $73 \%$ of non-generalised seizures. In a separate study by Leutmezer et al, ${ }^{76}$ of 145 seizures in 58 patients, tachycardia was observed in $86.9 \%$ of seizures. This was significantly more common with mesial TLE than with non-lesional TLE or extra-TLE. Including all studies, an increased heart rate has been recorded in $64-100 \%$ of seizures. ${ }^{76}$ Other than sinus tachycardia, ECG abnormalities have been observed in $21.5 \%$ of seizures and $37 \%$ of patients. ${ }^{34}$ These changes are mostly benign. Seizure-induced bradycardia is an infrequent event. In the study by Leutmezer et $a l,{ }^{76}$ bradycardia was observed in only $1.4 \%$ of seizures. Overall, it occurs in less than $2 \%$ of all seizures. Ictal asystole (commonly defined as RR intervals longer than 3-5 s) is extremely rare. Only 5 of 1244 patients exhibited asystole concurrent with an ictal event. ${ }^{77}$ A retrospective study of 6825 patients undergoing long-term video EEG monitoring reported that ictal asystole occurred in only $0.27 \%$ of patients. ${ }^{78}$ The rarity of asystole does make it a rational candidate for a mechanism of SUDEP or at least a subset of SUDEP cases.

Seizures can induce other ECG abnormalities in addition to changes in heart rate. In a study of 102 seizures and 41 patients, only 6 seizures $(6 \%)$ were associated with potentially serious ECG abnormalities occurring in only 4 patients $(10 \%) .^{75}$ These included ST segment depression and T-wave inversion. The benign abnormalities included premature atrial depolarisations, atrial bigeminy, premature ventricular depolarisations, ventricular couplets and first degree and second degree atrioventricular block, Mobitz I. In a study of 43 patients and 105 seizures, 
clinically significant ictal prolongation of the QTc interval using Bazett's formula was found in $16.2 \%$ of seizures, whereas shortened QTc intervals were observed in $4.8 \%$ of seizures. ${ }^{34}$

Unfortunately, many of these studies lacked measurements of respiratory rate, tidal volume, alveolar ventilation, oxygen saturation or other information about breathing. Therefore, it is unclear whether changes in heart rate, arrhythmias, asystole and other ECG abnormalities were secondary to seizure-induced respiratory changes. Hypoxaemia, hypoventilation and/or apnoea as well as other changes in breathing have known effects on heart rate and rhythm, likely through secondary autonomic changes. As discussed in the respiratory section, seizure-induced QT changes have been associated with seizure-induced hypoventilation and oxygen desaturation. ${ }^{56}$ Further supporting the suggestion that cardiac changes can sometimes be secondary to seizure-induced respiratory effects, in a study of over 250 seizures in 56 patients, one case of peri-ictal bradycardia was reportedly followed by asystole. ${ }^{31}$ In this case, the patient had concurrent oxygen desaturation to less than 50\%, suggesting that bradycardia and asystole may have been secondary to hypoxaemia due to hypoventilation.

\section{Heart rate variability}

Heart rate variability (HRV) is a measure of the beat-to-beat variability of the heart and results from modulation of the sinoatrial node by the autonomic nervous system. ${ }^{79}$ Reduced HRV has been associated with increased cardiac mortality and sudden cardiac death. ${ }^{79}$ Studies have shown that HRV is reduced in people with poorly controlled epilepsy compared with wellcontrolled participants and normal controls. ${ }^{80} 81$ A separate study showed that TLE was associated with reduced HR variability, which was more pronounced during the night than during the day. ${ }^{82}$ However, unlike previous studies, the alteration in autonomic regulation of HRV was similar in patients with both refractory and well-controlled TLE. ${ }^{82}$ Another study, although limited by small sample size, compared seven SUDEP cases with seven age-matched controls and found no difference in $\mathrm{HRV}^{83}$ Further study is needed to determine whether HRV plays a role in the pathophysiology of SUDEP or whether it may be a biomarker for SUDEP.

The cause of seizure-induced transient cardiac changes and reduced HRV is unclear, but is likely due to modulation of autonomic output. One possible mechanism is that seizures activate pathways that project to neurons in the brainstem that control autonomic output to the cardiovascular system. ${ }^{84}$ Others have suggested that transient cardiac effects and possibly reduced HRV are secondary to the response of the autonomic nervous system to apnoea and oxygen desaturation frequently seen in seizures. ${ }^{2}$ Further study of epilepsy patients and animal models is needed to define the mechanisms of seizure-induced cardiorespiratory effects, and the importance of these autonomic changes in the pathophysiology of SUDEP.

\section{Molecular mechanisms-ion channels}

Genetic mutations in ion channels that are expressed in the brain and heart may result in epilepsy. Evidence for this mostly comes from human genetic studies and rodent models containing these ion-channel mutations. In some of these mouse models, epilepsy occurs and seizures result in cardiac dysfunction that leads to death. Examples of these channelopathies include congenital long QT syndrome (LQTS), Dravet Syndrome and hyperSUMOylation of Kv7 channels present in the brain.

LQTS is an inherited cardiac disorder resulting in abnormal cardiac ventricular repolarisation characterised by QT interval prolongation and abnormal T-waves. ${ }^{85}$ LQTS patients are susceptible to polymorphic ventricular tachycardia and torsades de pointes, resulting in syncopal episodes and even sudden cardiac death in young, otherwise healthy individuals. A total of 15 genes have so far been implicated in LQTS pathogenesis. ${ }^{86}$ However, $90 \%$ of the genetically identified mutations are found in three genes and their encoded proteins. Two are potassium channels, Kv7.1 (KCNQ1; type 1 LQTS (LQT1)) and Kv11.1 (KCNH2; type 2 LQTS (LQT2)) and one is a sodium channel, Nav1.5 (SCN5A; type 3 LQTS (LQT3)). ${ }^{86}$

These ion channels are expressed in the heart, and their mutations were first identified as causing cardiac pathology, but many of these proteins are also expressed in the brain. Some patients with congenital LQTS, especially LQT2, have syncopal episodes that appear seizure-like, suggesting that some patients may actually have epilepsy as well. ${ }^{87}$ In a study of 610 patients with LQTS, $10(1.6 \%)$ patients were diagnosed with a seizure disorder by an epileptologist on the basis of clinical findings of seizures and EEG studies. ${ }^{86}$ Seven of the 10 patients had LQT2. Goldman $e t$ al $^{88}$ studied a LQTS mutation in Kv7.1 in mice and found that this potassium channel was expressed in the heart as well as neurons in the brain. EEG recordings from these mice revealed epileptiform discharges and appeared to have spontaneous seizures.

In summary, patients with congenital LQTS have increased risk of sudden death, and some patients with LQTS have been found to have epilepsy. ${ }^{86}$ However, it is unclear whether patients with congenital LQTS and epilepsy are at increased risk of SUDEP. Additionally, it is uncertain how many patients in previous SUDEP reports had concurrent congenital LQTS.

Dravet syndrome is a rare disorder that results in severe childhood-onset epilepsy characterised by febrile and afebrile, generalised and unilateral, clonic or tonic-clonic seizures that occur in the first year of life. ${ }^{89}$ As the children age beyond 1 year, they develop myoclonus, atypical absence and partial seizures. Unfortunately, all seizure types are resistant to AEDs and therefore risk of SUDEP is high, probably more than other infantile epilepsies, often occurring in young children ( $<5$ years) but also in adults. Developmental delay becomes apparent within the second year of life and is followed by cognitive impairment and personality disorders. ${ }^{89} 80 \%$ of patients with Dravet syndrome have a mutation in SCN1A, the gene that encodes the sodium channel $\mathrm{Na}_{\mathrm{v}} 1.1$ that is present in the brain and heart.

A mouse model of Dravet syndrome ( $\mathrm{Scn} 1 \mathrm{a}$ heterozygous $\mathrm{KO})$ recapitulates components of the human phenotype including epilepsy, and provides an avenue for understanding the pathophysiology of SUDEP. ${ }^{90}$ These mice have suppressed interictal resting HRV, episodes of ictal bradycardia that correlate with tonic phases of GTCS and death after prolonged ictal-onset bradycardia. Similar studies in conditional $\mathrm{KO}$ mice demonstrated that brain, but not cardiac, KO of $S c n 1 a$ produced cardiac and SUDEP phenotypes similar to those found in the Scn1a heterozygous DS mice. Muscarinic antagonists decrease bradycardia and seizure-induced death, suggesting that vagal parasympathetic output may cause lethal bradycardia in SUDEP. $^{90}$ However, because the study of this mouse model lacked respiratory monitoring during seizures, it is unclear if this mutation led to worsening respiratory dysfunction, and, additionally, whether these cardiac findings were secondary to seizure-induced hypoventilation and/or apnoea and oxygen desaturation. As discussed previously, apnoea associated with oxygen desaturation can lead to bradycardia.

Other ion channel modifications that result in epilepsy in mice have been discovered. Qi et $a l^{91}$ showed that deletion of 
SENP2 in the mouse brain resulted in hyper-SUMOylation of Kv7 channels. These mice developed spontaneous seizures, which resulted in cardiac abnormalities and death. Again, respiratory monitoring was not performed during seizures and the period of time proceeding death. Therefore, it is unclear whether apnoea and oxygen desaturation resulted in these cardiac changes, or whether the apnoea and oxygen desaturation was more severe because of the mutation.

\section{Summary}

Cardiac changes occur during seizures. Increasing evidence suggests genetic mutations in ion channels, present in the brain and heart, may increase the risk of epilepsy and SUDEP. Although rodent models with these genetic mutations demonstrate cardiac changes during seizures prior to death, it is unclear whether these cardiac events are caused by hypoventilation and oxygen desaturation during seizures. Future studies using a combination of cardiorespiratory monitoring in SUDEP animal models, similar to the study by Buchanan et al, ${ }^{71}$ will help clarify these issues.

\section{Electrocerebral shutdown}

PGES is diffuse flattening of the EEG in the postictal period and likely the result of a GTCS. ${ }^{92}$ Some have suggested 'electrocerebral shutdown', or prolonged PGES, as a causal mechanism of cardiorespiratory dysfunction and SUDEP. $^{93}$ However, it is unclear if prolonged PGES can directly cause cardiorespiratory dysfunction. Studies are inconsistent on whether the presence or duration of PGES is an independent risk factor for SUDEP. ${ }^{92} 93$ More research is needed to understand how PGES plays a role, if any, in the pathophysiology of SUDEP.

\section{Genetic susceptibility}

Genetic conditions such as Tuberous Sclerosis complex and Dravet syndrome contain mutations, which lead to medically refractory epilepsy and frequent seizures with an increased rate of SUDEP. However, it is unclear whether these mutations result in more frequent seizures that lead to an increased likelihood of SUDEP or whether these mutations result in an altered cardiorespiratory response to seizures. With future genetic studies and a better understanding of the pathophysiological mechanisms of
SUDEP, we will begin to parse out the genetics of SUDEP susceptibility.

\section{Other molecular mechanisms}

We previously discussed the role of serotonin dysfunction in the pathophysiology of SUDEP in the respiratory section as well as how ion-channel mutations expressed in the heart and brain may contribute to SUDEP in the cardiac section. Other molecular mechanisms may also play a role in cardiorespiratory changes. Adenosine has received a significant amount of attention since it was one of the first molecular mechanisms identified as a possible contributor to SUDEP. ${ }^{94}$

\section{Adenosine}

Adenosine is a modulator of synaptic transmission and neuronal activity, exerting most of its functions via activation of the excitatory and inhibitory adenosine receptors. ${ }^{95}$ Additionally, adenosine may have effects on brainstem mediated cardiorespiratory function. ${ }^{94}$ In a study by Shen et al, ${ }^{94}$ mice were treated with pharmacological inhibitors responsible for metabolising adenosine, after which seizures were induced. These mice were protected from seizures for the first $15 \mathrm{~min}$, but eventually developed seizures and died. If the mice were treated with caffeine (an adenosine receptor antagonist) at seizure onset, however, their survival time was significantly increased compared with their untreated counterparts. Shen and colleagues concluded that adenosine may contribute to seizure-induced death. More research is required on the effects of caffeine on cardiorespiratory function in the peri-ictal period in mouse models.

\section{Summary of SUDEP pathophysiology}

SUDEP likely occurs through multiple mechanisms (figure 3). However, evidence from witnessed ${ }^{11}$ and monitored EMU SUDEP cases $^{25}$ suggests that a majority of patients have substantial respiratory dysfunction at the initial stages of the terminal event. Prolonged respiratory difficulty is often not an early symptom of sudden cardiac death, but is instead typically followed by an increase in ventilation and then gasping (figure 4). ${ }^{96}$ Therefore, it is unlikely for SUDEP to be caused
Figure 3 Pathophysiological mechanisms underlying sudden unexpected death in epilepsy (SUDEP). SUDEP often results from a generalised tonic-clonic seizure, which leads to inhibition of specific midbrain and medulla mediated effects via an unknown pathway. Other factors shown may predispose these patients to SUDEP. LQTS, long QT syndrome; PGES, postictal generalised EEG suppression.

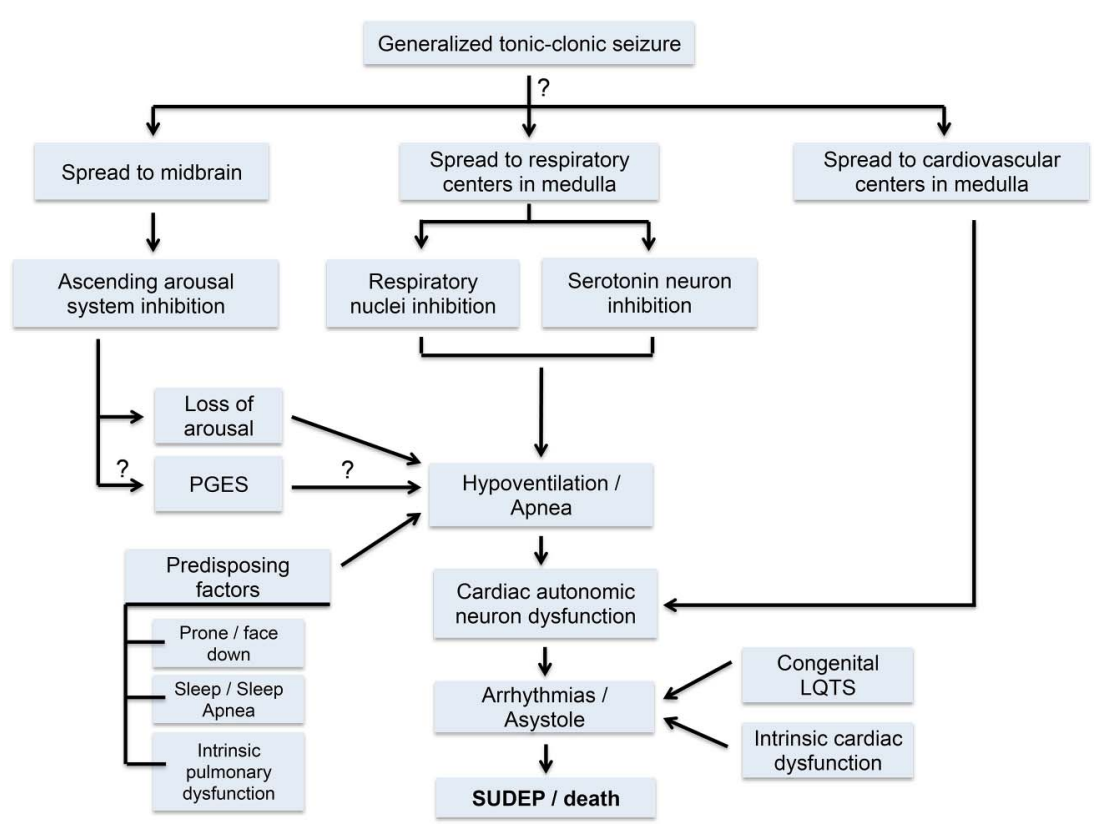


Figure 4 Respiratory response to sudden cardiac arrest. Recording of respiratory/ventilatory and circulatory responses to ventricular fibrillation (VF)-induced cardiac arrest (CA) in a sheep. From top to bottom, breath-by-breath respired $\mathrm{PCO}_{2}$, respiratory flow (inspiration (I) and expiration $(\mathrm{E}))$, tidal volume $\left(\mathrm{V}_{\mathrm{T}}\right)$, carotid blood pressure (ABP), respiratory rate in breaths per minute $(\mathrm{bpm})(\mathrm{f})$, and minute ventilation $\left(\mathrm{V}_{\mathrm{E}}\right)$ are shown. When VF was triggered (first vertical dotted line), blood pressure decreased to minimal levels, but ventilation remained elevated for 2 min, with an increase in both tidal volume and breathing frequency. During this period, alveolar $\mathrm{PCO}_{2}$ fell dramatically, and several augmented breaths can be observed. Apnoea then occurred followed by typical gasps. * Respiratory event triggered by the defibrillation procedure. Modified from Haouzi et al. ${ }^{96}$

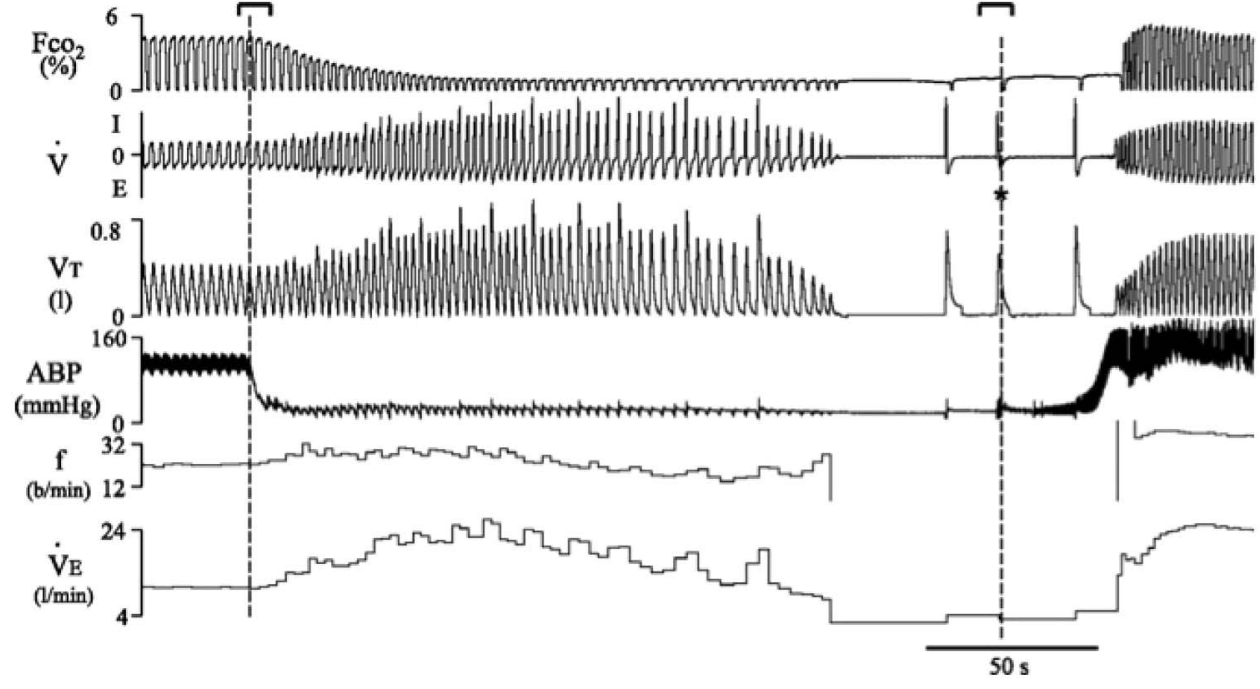

Using one or a combination of the more than 20 different AEDs currently available is the initial treatment for seizure control in epilepsy. Additionally, in the majority of epilepsy patients, AEDs decrease the risk of SUDEP. In a meta-analysis, adjunctive AED treatment appeared to reduce the risk of SUDEP more than sevenfold in patients with uncontrolled seizures. $^{18}$

Up to $30 \%$ of epilepsy patients have persistent seizures and develop medically intractable epilepsy. ${ }^{97}$ Attempting to continually treat patients whose seizures do not respond to the first few AEDs with all the various combinations of multiple AEDs is impractical and places the patient at undue risk. Medically intractable epilepsy patients are those who are at most risk of SUDEP. Early identification of patients who are refractory to two or more AEDs may be an important strategy to reduce their risk. ${ }^{97-99}$

Early surgical evaluation and intervention in adults and in children with medically intractable epilepsy has been shown to control seizures better than medical therapy alone. ${ }^{99}$ In addition, surgical treatment may also decrease SUDEP risk by decreasing seizure frequency or by other mechanisms. TLE surgery has been shown to significantly decrease SUDEP risk if seizures are eliminated. ${ }^{100}$ After TLE surgery, there is a reduction in sympathetic cardiovascular modulation and baroreflex sensitivity. ${ }^{101}$ This enhanced cerebrovascular stability after surgery may improve autonomic balance in epilepsy patients. ${ }^{101} 102$ Further study is needed to determine whether other surgical epilepsy procedures such as extratemporal lobe surgery, corpus callosotomies and hemispherectomies, among many others, are as effective. Although some of these surgical procedures may not lead to seizure freedom, surgical disruption of the neuronal circuitry in the brain may prove beneficial in disrupting the pathophysiological cardiorespiratory pathways thought to contribute to SUDEP. Further study is needed to determine which surgical epilepsy treatments reduce SUDEP risk. Not only would this provide additional treatment strategies, but may increase the pathophysiological understanding of SUDEP. 
Table 1 SUDEP preventative strategies

\begin{tabular}{|c|c|c|c|}
\hline Mechanism/risk factor & $\begin{array}{l}\text { Evidence-based SUDEP } \\
\text { preventative strategy }\end{array}$ & $\begin{array}{l}\text { Potential SUDEP preventative } \\
\text { strategy }\end{array}$ & Comment \\
\hline Epilepsy & $\mathrm{AEDs}^{18}$ & Newer AEDs & Sevenfold decrease in SUDEP risk with AEDS \\
\hline \multicolumn{4}{|l|}{ Intractable epilepsy } \\
\hline Surgical candidate & Temporal lobectomy for TLE ${ }^{100}$ & Other surgical epilepsy procedures & $\begin{array}{l}\text { If surgery eliminates seizures, SUDEP risk decreases } \\
\text { dramatically }\end{array}$ \\
\hline Non-surgical candidate & $\mathrm{AEDs}^{18}$ & Newer AEDs & $\begin{array}{l}\text { VNS decreases seizure frequency; may also have } \\
\text { autonomic effects on heart }\end{array}$ \\
\hline $\begin{array}{l}\text { Seizure-induced hypoventilation/ } \\
\text { apnoea }\end{array}$ & & $\begin{array}{l}\text { Pulse oxygenation alarms; seizure } \\
\text { alarms }\end{array}$ & $\begin{array}{l}\text { Development of practical, portable, wearable 'pulse } \\
\text { ox' }\end{array}$ \\
\hline Loss of arousal & Supervision ${ }^{14}$ & Seizure alarms-wearable, bed & $\begin{array}{l}\text { Supervision allows for repositioning to optimise } \\
\text { breathing }\end{array}$ \\
\hline Prone/face down & & Special bedding; sleeping supine & $\begin{array}{l}\text { Prevents asphyxia, allows for greater chest wall } \\
\text { movement }\end{array}$ \\
\hline Sleep/sleep apnoea & Supervision at night ${ }^{14}$ & $\begin{array}{l}\text { OSA treatment; CPAP; Implantable } \\
\text { upper airway stimulator }\end{array}$ & Upper airway stimulation experimental \\
\hline Intrinsic pulmonary dysfunction & & Medical management & \\
\hline $\begin{array}{l}\text { Seizure-induced cardiac arrhythmias/ } \\
\text { asystole }\end{array}$ & AICD & AICD & $\begin{array}{l}\text { Pacemakers prevent ictal asystole-induced syncope; } \\
\text { however, not shown to prevent SUDEP }\end{array}$ \\
\hline $\begin{array}{l}\text { Intrinsic cardiac dysfunction/acquired } \\
\text { autonomic dysfunction }\end{array}$ & & VN; optimise cardiac function & \\
\hline Congenital LQTS & & Medical management; AICD & \\
\hline
\end{tabular}

Unfortunately, many patients who undergo a presurgical evaluation are not found to be good candidates for resective surgical therapy intended to make them seizure-free. These patients are at the highest risk for SUDEP. Patients can then be offered additional AEDs or drug combinations, dietary therapy, vagal nerve stimulation (VNS) or palliative surgical therapy. Focal resection can be considered as a palliative surgery when seizure freedom is not otherwise expected, for example, in patients with bilateral seizure foci.

SUDEP may be the end result of autonomic effects on the heart (figure 1). Inhibiting these autonomic changes may decrease SUDEP risk. VNS is effective at decreasing seizure frequency in medically intractable epilepsy ${ }^{103} 104$ and has been shown to have autonomic effects on the heart. ${ }^{105}$ In fact, VNS is an active area of study in heart failure. ${ }^{105}$ Additionally, longterm VNS in rats increases 5-HT levels. ${ }^{106}$ Given that VNS can decrease seizure frequency, has autonomic effects on the heart, and may affect 5-HT levels, further study is needed to determine whether VNS could decrease SUDEP risk.

Improvements in AEDs will hopefully decrease seizure frequency and SUDEP risk with decreased pharmacological side effects. Surgical treatment of epilepsy is continuously evolving. Complication rates have decreased significantly over the past 30 years and permanent neurological deficits are rare compared with the long-term risks of intractable epilepsy. ${ }^{107}$ Advancements in keyhole craniotomy procedures and minimal access approaches have allowed for decreased hospital stay and recovery time. ${ }^{108}$

\section{Prevention of respiratory changes}

Preventing or minimising seizure-induced apnoea, hypoventilation and oxygen desaturation may preclude the secondary autonomic response, cardiac abnormalities and death. As discussed previously, fluoxetine and several other, but not all selective serotonin reuptake inhibit (SSRIs), reverse respiratory arrest in a mouse model of epilepsy. ${ }^{65-67}$ Translating this finding to humans, Bateman et $a l^{73}$ found that seizure-induced oxygen desaturation was significantly reduced in 87 seizures in 16 epilepsy patients taking SSRIs compared to 409 seizures in 57 epilepsy patients not taking SSRIs. Further study is needed to determine whether taking SSRIs is effective at preventing SUDEP. Supervision at night may be effective in decreasing SUDEP, ${ }^{14}$ presumably by allowing repositioning during seizures, inducing arousal and therefore stimulating breathing. In a retrospective study of 39 patients with 105 generalised convulsions, early peri-ictal nursing intervention was associated with a reduced duration of respiratory dysfunction and PGES. ${ }^{109}$ The institution of routine respiratory monitoring may prevent in-hospital deaths and ultimately lead to the identification of high-risk patients. Wearable and portable pulse oxygen saturation seizure alarms may provide a similar type of benefit, allowing family, friends or others to be alerted and to therefore reposition the patient for optimal breathing. The development of a diaphragmatic pacemaker ${ }^{110}$ that becomes activated during periods of prolonged apnoea or oxygen desaturation could also be of benefit. Treating obstructive sleep apnoea using a continuous positive airway pressure device ${ }^{111}$ or with an upper airway implantable stimulation device ${ }^{112}$ could also decrease SUDEP risks by mitigating a contributing SUDEP risk factor for epilepsy patients.

\section{Prevention of cardiac changes}

The events leading to cardiac arrhythmias, asystole and cardiac failure are uncertain, but as discussed previously, occur either secondary to respiratory dysfunction or from primary seizureinduced autonomic cardiac effects. Regardless, preventing the bradyarrhythmias, asystole or tachyarrhythmias associated with these autonomic changes, may prevent death. In patients presenting initially with concerns of seizures and possibly epilepsy, ECG evaluation is critical as syncopal episodes from LQTS can be misdiagnosed as seizures. Additionally, as noted, some patients with congenital LQTS have epilepsy as well. These 
patients may be at high risk for SUDEP. Treating the LQTS may prevent sudden death in these patients. Multiple case reports have implanted cardiac pacemakers after finding substantial periods of ictal asystole. However, no large study of epilepsy patients with an implanted automatic implantable cardioverter defibrillator (AICD) has been conducted demonstrating prevention of SUDEP. It would not be prudent to implant cardiac pacemakers and cardiac defibrillators in all epilepsy patients. Further knowledge is needed to refine which patients are at highest risk, as these patients may benefit from an AICD. However, if the initiating and primary event that leads to cardiac dysfunction is respiratory dysfunction, cardiac pacing or defibrillation will not correct the oxygen desaturation leading to autonomic changes. In these cases, if oxygen saturation is not improved, maintaining a normal heart rhythm may prove challenging. An on-demand diaphragmatic pacemaker may be an effective way to prevent the hypoventilation that can occur in some patients after a seizure.

\section{Seizure alarms}

Using seizure alarms to alert family members, medical personnel or others that an epilepsy patient is having a seizure may be beneficial in reducing respiratory dysfunction and oxygen desaturation as well as allowing for resuscitatory measures, thereby preventing SUDEP. As discussed above, early peri-ictal nursing intervention was associated with a reduced duration of respiratory dysfunction ${ }^{109}$ and supervision at night was protective against SUDEP. ${ }^{14}$ Seizure alarms studied include a wireless wrist accelerometer sensor that detects GTCS with high sensitivity and specificity. ${ }^{113}$ Another seizure alarm that has been studied is an under-mattress device, ${ }^{114}$ which is triggered by rhythmic motor activity of a specifiable duration, frequency and intensity using a quasi-piezoelectric material sensitive to changes in mattress pressure.

\section{CONCLUSION}

The pathophysiology underlying SUDEP appears complex. Analysing and incorporating the various studies on SUDEP have helped elucidate cardiorespiratory mechanisms and predisposing factors. Ultimately, understanding the intricate mechanisms involved in SUDEP will lead to development of effective preventative strategies.

Contributors BJD, BKG and GBR wrote and edited the manuscript.

Competing interests None declared.

Provenance and peer review Commissioned; externally peer reviewed.

\section{REFERENCES}

1 Shorvon S, Tomson T. Sudden unexpected death in epilepsy. Lancet 2011:378:2028-38.

2 Massey CA, Sowers LP, Dlouhy BJ, et al. Mechanisms of sudden unexpected death in epilepsy: the pathway to prevention. Nat Rev Neurol 2014;10:271-82.

3 Nashef L. Sudden unexpected death in epilepsy: terminology and definitions. Epilepsia 1997:38(11 Suppl):S6-8

4 Schraeder PL, Delin K, McClelland RL, et al. Coroner and medical examiner documentation of sudden unexplained deaths in epilepsy. Epilepsy Res 2006:68:137-43.

5 Tomson T, Walczak T, Sillanpaa M, et al. Sudden unexpected death in epilepsy: a review of incidence and risk factors. Epilepsia 2005:46(11 Suppl):54-61.

6 Ficker DM, So EL, Shen WK, et al. Population-based study of the incidence of sudden unexplained death in epilepsy. Neurology 1998:51:1270-4.

7 Sillanpaa M, Shinnar S. Long-term mortality in childhood-onset epilepsy. N Engl J Med 2010;363:2522-9.

8 Thurman DJ, Hesdorffer DC, French JA. Sudden unexpected death in epilepsy: assessing the public health burden. Epilepsia 2014;55:1479-85.
9 Nashef L, Garner S, Sander JW, et al. Circumstances of death in sudden death in epilepsy: interviews of bereaved relatives. J Neurol Neurosurg Psychiatry 1998;64:349-52.

10 Kloster R, Engelskjon T. Sudden unexpected death in epilepsy (SUDEP): a clinical perspective and a search for risk factors. J Neurol Neurosurg Psychiatry 1999:67:439-44.

11 Langan Y, Nashef L, Sander JW. Sudden unexpected death in epilepsy: a series of witnessed deaths. I Neurol Neurosurg Psychiatry 2000;68:211-13.

12 Hesdorffer DC, Tomson T, Benn E, et al. Combined analysis of risk factors for SUDEP. Epilepsia 2011;52:1150-9.

13 Aurlien D, Larsen JP, Gjerstad L, et al. Increased risk of sudden unexpected death in epilepsy in females using lamotrigine: a nested, case-control study. Epilepsia 2012:53:258-66

14 Langan Y, Nashef L, Sander JW. Case-control study of SUDEP. Neurology 2005;64:1131-3.

15 Timmings PL. Sudden unexpected death in epilepsy: a local audit. Seizure 1993:2:287-90.

16 Leestma JE, Annegers JF, Brodie MJ, et al. Sudden unexplained death in epilepsy: observations from a large clinical development program. Epilepsia 1997;38:47-55.

17 Tomson T, Hirsch LJ, Friedman D, et al. Sudden unexpected death in epilepsy in lamotrigine randomized-controlled trials. Epilepsia 2013;54:135-40.

18 Ryvlin P, Cucherat M, Rheims S. Risk of sudden unexpected death in epilepsy in patients given adjunctive antiepileptic treatment for refractory seizures: a meta-analysis of placebo-controlled randomised trials. Lancet Neurol 2011;10:961-8.

19 Hesdorffer DC, Tomson T. Sudden unexpected death in epilepsy. Potential role of antiepileptic drugs. CNS Drugs 2013;27:113-19.

20 Bateman LM, Spitz M, Seyal M. Ictal hypoventilation contributes to cardiac arrhythmia and SUDEP: report on two deaths in video-EEG-monitored patients. Epilepsia 2010;51:916-20.

21 Tao JX, Qian S, Baldwin M, et al. SUDEP, suspected positional airway obstruction, and hypoventilation in postictal coma. Epilepsia 2010;51:2344-7.

22 Purves SJ, Wilson-Young M, Sweeney VP. Sudden death in epilepsy: single case report with video-EEG documentation. Epilepsia 1992;33(Suppl 3):123.

23 Bird JM, Dembny AT, Sandeman D, et al. Sudden unexplained death in epilepsy: an intracranialy monitored case. Epilepsia 1997;38(Suppl 11):S52-6.

24 McLean BN, Wimalaratna S. Sudden death in epilepsy recorded in ambulatory EEG. J Neurol Neurosurg Psychiatry 2007;78:1395-7.

25 Ryvlin $\mathrm{P}$, Nashef L, Lhatoo SD, et al. Incidence and mechanisms of cardiorespiratory arrests in epilepsy monitoring units (MORTEMUS): a retrospective study. Lancet Neurol 2013;12:966-77.

26 Jackson J. On asphyxia in slight epileptic paroxysms. Lancet 1899;153:79-80.

27 Watanabe K, Hara K, Hakamada S, et al. Seizures with apnea in children. Pediatrics 1982:70:87-90.

28 James MR, Marshall H, Carew-McColl M. Pulse oximetry during apparent tonic-clonic seizures. Lancet 1991;337:394-5.

29 Hewertson J, Poets CF, Samuels MP, et al. Epileptic seizure-induced hypoxemia in infants with apparent life-threatening events. Pediatrics 1994;94(2 Pt 1):148-56.

30 Nashef L, Walker F, Allen P, et al. Apnoea and bradycardia during epileptic seizures: relation to sudden death in epilepsy. I Neurol Neurosurg Psychiatry 1996;60:297-300.

31 Bateman LM, Li CS, Seyal M. Ictal hypoxemia in localization-related epilepsy: analysis of incidence, severity and risk factors. Brain 2008;131(Pt 12):3239-45.

32 Seyal M, Bateman LM, Albertson TE, et al. Respiratory changes with seizures in localization-related epilepsy: analysis of periictal hypercapnia and airflow patterns. Epilepsia 2010;51:1359-64

33 Moseley BD, Nickels K, Britton J, et al. How common is ictal hypoxemia and bradycardia in children with partial complex and generalized convulsive seizures? Epilepsia 2010;51:1219-24

34 Moseley BD, Wirrell EC, Nickels K, et al. Electrocardiographic and oximetric changes during partial complex and generalized seizures. Epilepsy Res 2011;95:237-45.

35 O'Regan ME, Brown JK. Abnormalities in cardiac and respiratory function observed during seizures in childhood. Dev Med Child Neurol 2005:47:4-9.

36 Seyal M, Hardin KA, Bateman LM. Postictal generalized EEG suppression is linked to seizure-associated respiratory dysfunction but not postictal apnea. Epilepsia 2012;53:825-31.

37 Terrence CF, Rao GR, Perper JA. Neurogenic pulmonary edema in unexpected, unexplained death of epileptic patients. Ann Neurol 1981;9:458-64.

38 Leestma JE, Walczak T, Hughes JR, et al. A prospective study on sudden unexpected death in epilepsy. Ann Neurol 1989;26:195-203.

39 Earnest MP, Thomas GE, Eden RA, et al. The sudden unexplained death syndrome in epilepsy: demographic, clinical, and postmortem features. Epilepsia 1992:33:310-16.

40 Buchanan GF, Richerson GB. Central serotonin neurons are required for arousal to CO2. Proc Natl Acad Sci USA 2010;107:16354-9.

41 Severson CA, Wang W, Pieribone VA, et al. Midbrain serotonergic neurons are central pH chemoreceptors. Nat Neurosci 2003;6:1139-40. 
42 Richerson GB. Serotonergic neurons as carbon dioxide sensors that maintain $\mathrm{pH}$ homeostasis. Nat Rev Neurosci 2004;5:449-61.

43 Lamberts RJ, Thijs RD, Laffan A, et al. Sudden unexpected death in epilepsy: people with nocturnal seizures may be at highest risk. Epilepsia 2012;53:253-7.

44 Phillipson EA. Control of breathing during sleep. Am Rev Respir Dis 1978:118:909-39.

45 White DP, Douglas NJ, Pickett CK, et al. Hypoxic ventilatory response during sleep in normal premenopausal women. Am Rev Respir Dis 1982;126:530-3.

46 Douglas NJ, White DP, Weil JV, et al. Hypoxic ventilatory response decreases during sleep in normal men. Am Rev Respir Dis 1982;125:286-9.

47 Wiegand L, Zwillich CW, White DP. Sleep and the ventilatory response to resistive loading in normal men. J Appl Physiol (1985) 1988;64:1186-95.

48 Horner RL, Hughes SW, Malhotra A. State-dependent and reflex drives to the upper airway: basic physiology with clinical implications. J App/ Physiol (1985) 2014;116:325-36.

49 Malow BA, Levy K, Maturen K, et al. Obstructive sleep apnea is common in medically refractory epilepsy patients. Neurology 2000;55:1002-7.

50 Foldvary-Schaefer N, Andrews ND, Pornsriniyom D, et al. Sleep apnea and epilepsy: who's at risk? Epilepsy Behav 2012;25:363-7.

51 Chihorek AM, Abou-Khalil B, Malow BA. Obstructive sleep apnea is associated with seizure occurrence in older adults with epilepsy. Neurology 2007;69:1823-7.

52 Quigg M, Straume M, Menaker M, et al. Temporal distribution of partial seizures: comparison of an animal model with human partial epilepsy. Ann Neurol 1998:43:748-55

53 Yi PL, Chen YJ, Lin CT, et al. Occurrence of epilepsy at different zeitgeber times alters sleep homeostasis differently in rats. Sleep 2012:35:1651-65.

54 Spengler CM, Czeisler CA, Shea SA. An endogenous circadian rhythm of respiratory control in humans. J Physiol 2000:526(Pt 3):683-94.

55 Schafer T. Variability of vigilance and ventilation: studies on the control of respiration during sleep. Respir Physiol 1998;114:37-48.

56 Seyal M, Pascual F, Lee CY, et al. Seizure-related cardiac repolarization abnormalities are associated with ictal hypoxemia. Epilepsia 2011:52:2105-11.

57 Kato $\mathrm{H}$, Menon AS, Slutsky AS. Mechanisms mediating the heart rate response to hypoxemia. Circulation 1988;77:407-14.

58 Kara T, Narkiewicz K, Somers VK. Chemoreflexes_-physiology and clinical implications. Acta Physio/ Scand 2003;177:377-84.

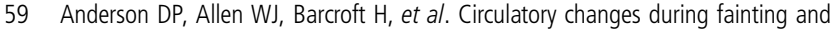
coma caused by oxygen lack. J Physiol 1946;104:426-34.

60 Marshall JM. The Joan Mott Prize Lecture. The integrated response to hypoxia: from circulation to cells. Exp Physiol 1999;84:449-70.

61 Seyal M, Bateman LM. Ictal apnea linked to contralateral spread of temporal lobe seizures: intracranial EEG recordings in refractory temporal lobe epilepsy. Epilepsia 2009;50:2557-62

62 Kaada BR, Jasper $H$. Respiratory responses to stimulation of temporal pole, insula, and hippocampal and limbic gyri in man. AMA Arch Neurol Psychiatry 1952;68:609-19.

63 Faingold CL, Randall M, Tupal S. DBA/1 mice exhibit chronic susceptibility to audiogenic seizures followed by sudden death associated with respiratory arrest. Epilepsy Behav 2010;17:436-40.

64 Venit EL, Shepard BD, Seyfried TN. Oxygenation prevents sudden death in seizure-prone mice. Epilepsia 2004;45:993-6.

65 Faingold CL, Tupal S, Randall M. Prevention of seizure-induced sudden death in a chronic SUDEP model by semichronic administration of a selective serotonin reuptake inhibitor. Epilepsy Behav 2011;22:186-90.

66 Faingold $\mathrm{CL}$, Kommajosyula SP, Long $\mathrm{X}$, et al. Serotonin and sudden death: differential effects of serotonergic drugs on seizure-induced respiratory arrest in DBA/1 mice. Epilepsy Behav 2014;37:198-203.

67 Tupal S, Faingold CL. Evidence supporting a role of serotonin in modulation of sudden death induced by seizures in DBA/2 mice. Epilepsia 2006;47:21-6.

68 Faingold CL, Randall M, Mhaskar Y, et al. Differences in serotonin receptor expression in the brainstem may explain the differential ability of a serotonin agonist to block seizure-induced sudden death in DBA/2 vs. DBA/1 mice. Brain Res 2011;1418:104-10.

69 Teran FA, Massey CA, Richerson GB. Serotonin neurons and central respiratory chemoreception: where are we now? Prog Brain Res 2014;209:207-33.

70 Hodges MR, Tattersall GJ, Harris MB, et al. Defects in breathing and thermoregulation in mice with near-complete absence of central serotonin neurons. J Neurosci 2008;28:2495-505.

71 Buchanan GF, Murray NM, Hajek MA, et al. Serotonin neurones have anti-convulsant effects and reduce seizure-induced mortality. J Physio/ 2014;592(Pt 19):4395-410.

72 Tecott LH, Sun LM, Akana SF, et al. Eating disorder and epilepsy in mice lacking 5-HT2C serotonin receptors. Nature 1995:374:542-6.

73 Bateman LM, Li CS, Lin TC, et al. Serotonin reuptake inhibitors are associated with reduced severity of ictal hypoxemia in medically refractory partial epilepsy. Epilepsia 2010;51:2211-14.

74 Mueller SG, Bateman LM, Laxer KD. Evidence for brainstem network disruption in temporal lobe epilepsy and sudden unexplained death in epilepsy. Neuro Image Clin 2014;5:208-16
75 Opherk C, Coromilas J, Hirsch LJ. Heart rate and EKG changes in 102 seizures: analysis of influencing factors. Epilepsy Res 2002;52:117-27.

76 Leutmezer F, Schernthaner $C$, Lurger $S$, et al. Electrocardiographic changes at the onset of epileptic seizures. Epilepsia 2003:44:348-54.

77 Rocamora R, Kurthen M, Lickfett L, et al. Cardiac asystole in epilepsy: clinical and neurophysiologic features. Epilepsia 2003;44:179-85.

78 Schuele SU, Bermeo AC, Alexopoulos AV, et al. Video-electrographic and clinical features in patients with ictal asystole. Neurology 2007;69:434-41.

79 Stein PK, Kleiger RE. Insights from the study of heart rate variability. Annu Rev Med 1999:50:249-61.

80 Ansakorpi $\mathrm{H}$, Korpelainen JT, Huikuri HV, et al. Heart rate dynamics in refractory and well controlled temporal lobe epilepsy. J Neurol Neurosurg Psychiatry 2002:72:26-30.

81 Mukherjee S, Tripathi M, Chandra PS, et al. Cardiovascular autonomic functions in well-controlled and intractable partial epilepsies. Epilepsy Res 2009:85:261-9.

82 Ronkainen E, Ansakorpi H, Huikuri HV, et al. Suppressed circadian heart rate dynamics in temporal lobe epilepsy. J Neurol Neurosurg Psychiatry 2005;76:1382-6.

83 Surges $\mathrm{R}$, Henneberger $\mathrm{C}$, Adjei $\mathrm{P}$, et al. Do alterations in inter-ictal heart rate variability predict sudden unexpected death in epilepsy? Epilepsy Res 2009;87:277-80.

84 Devinsky 0. Effects of seizures on autonomic and cardiovascular function. Epilepsy Curr 2004;4:43-6.

85 Goldenberg I, Moss AJ. Long QT syndrome. J Am Coll Cardiol 2008;51:2291-300.

86 Anderson JH, Bos JM, Cascino GD, et al. Prevalence and spectrum of electroencephalogram-identified epileptiform activity among patients with long QT syndrome. Heart Rhythm 2014;11:53-7.

87 Johnson JN, Hofman N, Haglund CM, et al. Identification of a possible pathogenic link between congenital long QT syndrome and epilepsy. Neurology 2009;72:224-31.

88 Goldman AM, Glasscock E, Yoo J, et al. Arrhythmia in heart and brain: KCNQ1 mutations link epilepsy and sudden unexplained death. Sci Trans/ Med 2009; 1:2ra6.

89 Dravet C, Oguni H. Dravet syndrome (severe myoclonic epilepsy in infancy). Handb Clin Neurol 2013;111:627-33

90 Kalume F, Westenbroek RE, Cheah CS, et al. Sudden unexpected death in a mouse model of Dravet syndrome. J Clin Invest 2013;123:1798-808.

91 Qi Y, Wang J, Bomben VC, et al. Hyper-SUMOylation of the Kv7 potassium channel diminishes the M-current leading to seizures and sudden death. Neuron 2014:83:1159-71.

92 Surges R, Strzelczyk A, Scott CA, et al. Postictal generalized electroencephalographic suppression is associated with generalized seizures. Epilepsy Behav 2011;21:271-4.

93 Lhatoo SD, Faulkner HJ, Dembny K, et al. An electroclinical case-control study of sudden unexpected death in epilepsy. Ann Neurol 2010:68:787-96.

94 Shen HY, Li T, Boison D. A novel mouse model for sudden unexpected death in epilepsy (SUDEP): role of impaired adenosine clearance. Epilepsia 2010;51:465-8

95 Boison D. The adenosine kinase hypothesis of epileptogenesis. Prog Neurobiol 2008:84:249-62.

96 Haouzi P, Ahmadpour N, Bell HJ, et al. Breathing patterns during cardiac arrest. J Appl Physiol (1985) 2010;109:405-11.

97 Kwan P, Brodie MJ. Early identification of refractory epilepsy. N Engl J Med 2000;342:314-19.

98 Wiebe S, Blume WT, Girvin JP, et al. A randomized, controlled trial of surgery for temporal-lobe epilepsy. N Engl J Med 2001;345:311-18.

99 Engel J, Jr., McDermott MP, Wiebe $S$, et al. Early surgical therapy for drug-resistant temporal lobe epilepsy: a randomized trial. JAMA 2012;307:922-30.

100 Sperling MR, Harris A, Nei M, et al. Mortality after epilepsy surgery. Epilepsia 2005;46(Suppl 11):49-53.

101 Hilz MJ, Devinsky O, Doyle W, et al. Decrease of sympathetic cardiovascular modulation after temporal lobe epilepsy surgery. Brain 2002;125(Pt 5):985-95.

102 Dutsch M, Devinsky O, Doyle W, et al. Cerebral autoregulation improves in epilepsy patients after temporal lobe surgery. J Neurol 2004;251:1190-7.

103 Ben-Menachem E, Manon-Espaillat R, Ristanovic R, et al. Vagus nerve stimulation for treatment of partial seizures: 1. A controlled study of effect on seizures. First International Vagus Nerve Stimulation Study Group. Epilepsia 1994;35:616-26.

104 [No authors listed]. A randomized controlled trial of chronic vagus nerve stimulation for treatment of medically intractable seizures. The Vagus Nerve Stimulation Study Group. Neurology 1995;45:224-30.

105 De Ferrari GM, Crijns HJ, Borggrefe $M$, et al. Chronic vagus nerve stimulation: a new and promising therapeutic approach for chronic heart failure. Eur Heart J 2011;32:847-55.

106 Manta S, El Mansari M, Debonnel G, et al. Electrophysiological and neurochemical effects of long-term vagus nerve stimulation on the rat monoaminergic systems. Int J Neuropsychopharmacol 2013;16:459-70. 
107 Tebo CC, Evins Al, Christos PJ, et al. Evolution of cranial epilepsy surgery complication rates: a 32-year systematic review and meta-analysis. J Neurosurg 2014;120:1415-27.

108 Little AS, Smith KA, Kirlin K, et al. Modifications to the subtemporal selective amygdalohippocampectomy using a minimal-access technique: seizure and neuropsychological outcomes. J Neurosurg 2009:111:1263-74.

109 Seyal M, Bateman LM, Li CS. Impact of periictal interventions on respiratory dysfunction, postictal EEG suppression, and postictal immobility. Epilepsia 2013;54:377-82.

110 Moxham J, Shneerson JM. Diaphragmatic pacing. Am Rev Respir Dis 1993;148:533-6.
111 Devinsky O, Ehrenberg B, Barthlen GM, et al. Epilepsy and sleep apnea syndrome. Neurology 1994;44:2060-4.

112 Strollo PJ, Jr., Soose RJ, Maurer JT, et al. Upper-airway stimulation for obstructive sleep apnea. N Engl J Med 2014;370:139-49.

113 Beniczky S, Polster T, Kjaer TW, et al. Detection of generalized tonic-clonic seizures by a wireless wrist accelerometer: a prospective, multicenter study. Epilepsia 2013;54:e58-61

114 Narechania AP, Garic II, Sen-Gupta I, et al. Assessment of a quasi-piezoelectric mattress monitor as a detection system for generalized convulsions. Epilepsy Behav 2013:28:172-6. 